Received 00th January 20xx, Accepted 00th January 20xx

DOI: $10.1039 / \times 0 \times x 00000 x$

\title{
Quenching of the Phosphorescence of Thermally Reversible Photochromic Naphthopyran Re(I) Complexes Initiated by either Visible or Ultraviolet Radiation
}

\author{
Orlando D.C.C. De Azevedo*a, Paul I.P. Elliott*a, Christopher D. Gabbutta, B. Mark Heron*a, Denis \\ Jacquemin $^{* b}$, Craig R. Rice ${ }^{\text {a }}$ Paul A. Scattergood ${ }^{\mathrm{a}}$
}

$\operatorname{Re}($ I) complexes bearing thermally reversible photochromic naphthopyran axial ligands undergo highly efficient, reversible phosphorescence quenching actuated by either visible or UV irradiation. The photoinduced quenching of the triplet metal-toligand charge-transfer ( ${ }^{3} \mathrm{MLCT}$ ) emission is interpreted based on changes in the relative energies of the excited states.

The development of transition metal (TM) complexes that incorporate photochromic ligands has received significant interest in the last two decades. ${ }^{1}$ Incorporation of the photochromic moiety either by coordination to the metal centre or by covalently binding it to a coordinated ligand has been shown to perturb the photochromic properties. ${ }^{2}$ Additionally, the photochromic reaction has been reported to modulate and/or switch the luminescence of the transition metal complexes. Photoresponsive ligands, activated by UV irradiation, employed to date include dithienylethenes, ${ }^{3}$ azobenzenes, ${ }^{4}$ spirooxazines, ${ }^{5}$ viologens ${ }^{6}$ and a selection of metal centres including $\mathrm{Co},{ }^{7} \mathrm{Zn},{ }^{8} \mathrm{Mo},{ }^{9} \mathrm{Ru},{ }^{10} \mathrm{Rh},{ }^{11} \mathrm{Pd} / \mathrm{Pt},{ }^{12} \mathrm{Ag},{ }^{13}$ $\mathrm{Cd}^{14} \mathrm{Re},{ }^{15} \mathrm{Ir},{ }^{16} \mathrm{Au},{ }^{17}$ have been investigated. Thermally reversible, UV activated photochromic naphthopyrans, whilst established in ophthalmic sunlenses and variable transmission filters, ${ }^{18}$ remain unexplored as photoresponsive ligands to modulate the luminescence of TM complexes. Herein, we describe the synthesis and photophysical properties of the first $\operatorname{Re}(\mathrm{I})$ complexes containing $3 H$-naphtho[2,1-b]pyrans (NP) as photochromic ancillary ligands that allow the highly efficient, reversible off/on switching of the metal complex phosphorescence remarkably triggered by visible light, or more routinely by UV irradiation, leading to a dual wavelength photoswitching system.

a Dr O.D.C.C. De Azevedo, Prof. P.I.P. Elliott, Prof. B.M. Heron Dr C.D. Gabbutt, Prof. C.R. Rice, Dr P.A. Scattergood

Department of Chemical Sciences, School of Applied Sciences University of Huddersfield, Queensgate, Huddersfield, HD1 3DH, UK.

b Prof. D. Jacquemin

Université de Nantes, CNRS, CEISAM UMR 6230, Nantes, France.

E-mail: O.DeAzevedo2@hud.ac.uk; p.i.elliott@hud.ac.uk; m.heron@hud.ac.uk; denis.jacquemin@univ-nantes.fr.

Electronic Supplementary Information (ESI) available: [details of any supplementary information available should be included here]. See DOI: 10.1039/x0xx00000x
By taking advantage of the trans influence, the chloride ligand of the fac- $\left[\operatorname{Re}\left(\mathrm{N}^{\wedge} \mathrm{N}\right)(\mathrm{CO})_{3} \mathrm{Cl}\right]^{0}$ complexes 1a $\left[\mathrm{N}^{\wedge} \mathrm{N}=1\right.$-benzyl-4(2-pyridyl)-1,2,3-triazole (pytz)] and $\mathbf{1 b}\left[\mathrm{N}^{\wedge} \mathrm{N}=2,2^{\prime}\right.$-bipyridine (bpy)] was substituted ${ }^{19}$ by the 8-(4-pyridyl)-3H-naphtho[2,1b]pyrans $\mathbf{2} \mathbf{a}$ and $\mathbf{2} \mathbf{b}$, the latter prepared by our literature protocol, ${ }^{20}$ in the presence of $\mathrm{AgPF}_{6}$, affording the fac$\left[\operatorname{Re}\left(\mathrm{N}^{\wedge} \mathrm{N}\right)(\mathrm{CO})_{3} \mathrm{NP}\right]^{+}$complexes $3 \mathrm{a}-3 \mathrm{c} \quad(27-75 \%$ yield $)$. Characterization by NMR, HRMS and FT-IR was supplemented by an X-ray crystal structure for $\mathbf{3 c}$ that confirmed the approximately octahedral geometry of the rhenium centre and the facial configuration of the carbonyl ligands.

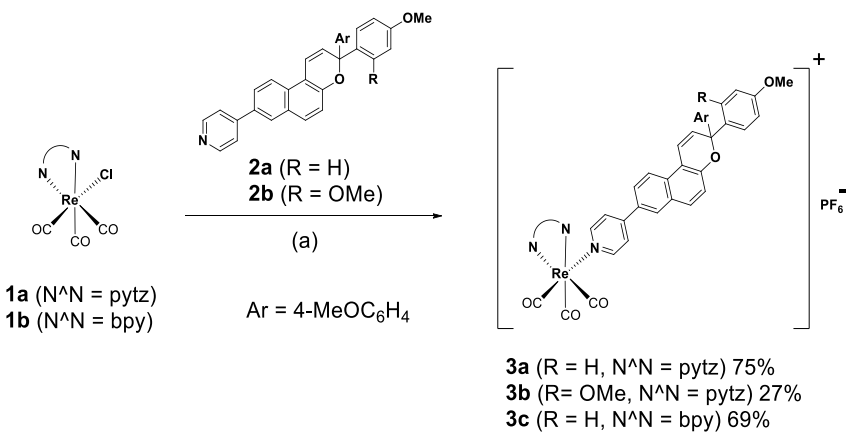

Scheme 1 Reagents and conditions: (a) $\mathrm{AgPF}_{6}, \mathrm{DCM}$, dark, N2, rt.

Complexes $\mathbf{3 a} \mathbf{- 3} \mathbf{c}$ produced pale yellow solutions in acetonitrile with a broad absorption band centred at 346-350 $\mathrm{nm}$ with large $\varepsilon=1.6-3.3 \times 10^{4} \mathrm{M}^{-1} . \mathrm{cm}^{-1}$ (Table 1 and Fig. 1). For 3a, the two lowest dipole-allowed transitions found in the vertical TD-DFT spectrum are located at $382 \mathrm{~nm}[\mathrm{f}=0.004]$ and $390 \mathrm{~nm}[\mathrm{f}=$ 0.334], corresponding respectively to a HOMO (NP) to LUMO (pytz) transition with a small HOMO-3 (Re) to LUMO (pytz) contribution, and to a HOMO (NP) to LUMO+1 (NP/py) excitation (Fig. S56). The difference between theory (390 nm) and experiment ( $350 \mathrm{~nm}$ ), ca. $0.35 \mathrm{eV}$, is quite usual for this level of theory and the selected functional. For $\mathbf{3 c}$, the two lowest dipole-allowed transitions are located at $390 \mathrm{~nm}[\mathrm{f}=0.329$, $\mathrm{HOMO}(\mathrm{NP})$ to LUMO+1 (NP/bpy)] and $430 \mathrm{~nm}[\mathrm{f}=0.001$, HOMO (NP) to LUMO (bpy)] (Fig. S57). 
Table 1 Summary of photophysical data of the $f a c-\left[\operatorname{Re}\left(\mathrm{N}^{\wedge} \mathrm{N}\right)(\mathrm{CO}){ }_{3} \mathrm{NP}\right]^{+}$complexes $3 a-3 c$ in degassed acetonitrile.

\begin{tabular}{|c|c|c|c|c|c|c|c|c|}
\hline & $\lambda_{\max }^{[a]} / \mathrm{nm}\left(\varepsilon^{[\mathrm{b}]} / \mathrm{M}^{-1} \mathrm{~cm}^{-1}\right)$ & $\lambda_{\mathrm{em}}^{[\mathrm{cl}]} / \mathrm{nm}\left(\lambda_{\mathrm{exc}}{ }^{[\mathrm{d}]} / \mathrm{nm}\right)$ & $\Phi_{\mathrm{em}}^{[\mathrm{el}} / \%(\tau / \mathrm{ns})$ & $\lambda_{\mathrm{PSS}}{ }^{[\mathrm{f}]} / \mathrm{nm}$ & $\Delta \mathrm{A}_{\text {conc }}{ }^{[\mathrm{g}]} / \mathrm{M}^{-1}$ & $\mathrm{k}_{\Delta}{ }^{[\mathrm{h}]} / \mathrm{s}^{-1}$ (Amplitude/\%) & $\mathrm{t} / \mathrm{[ij}^{[\mathrm{ij}} / \mathrm{s}$ & $\mathrm{EQ}^{[\mathrm{j}]} / \%$ \\
\hline $3 a$ & $350\left(3.3 \times 10^{4}\right)$ & $490(392)$ & $0.8(4,71,551)$ & 490 & $2.7 \times 10^{4}$ & $\begin{array}{c}3.6 \times 10^{-1}(2) \\
1.3 \times 10^{-4}(98)\end{array}$ & 5531 & $85^{[l]}$ \\
\hline $3 b$ & $346\left(1.6 \times 10^{4}\right)$ & $500(382)$ & $0.6(5,74,469)$ & 490 & $1.4 \times 10^{4}$ & $\begin{array}{l}5.7 \times 10^{-1}(36) \\
3.0 \times 10^{-4}(64)\end{array}$ & 1165 & $\begin{array}{l}87^{[k]} \\
79^{[l]}\end{array}$ \\
\hline $3 c$ & $350\left(1.6 \times 10^{4}\right)$ & $603(394)$ & $0.2(7,36,280)$ & 490 & $1.0 \times 10^{4}$ & $\begin{array}{c}7.4 \times 10^{-1}(3) \\
3.2 \times 10^{-4}(97)\end{array}$ & 2034 & $12^{[k]}$ \\
\hline
\end{tabular}

[a] $\lambda_{\max }=$ maximum wavelength of absorption. [b] $\varepsilon=$ molar attenuation coefficient. [c] $\lambda_{\mathrm{em}}=$ maximum wavelength of emission. [d] $\lambda_{\mathrm{exc}}=$ excitation wavelength. [e] $\Phi_{\mathrm{em}}=$ quantum yield of emission. [f] $\lambda_{\text {PSS }}=$ maximum wavelength of absorption at the PSS. [g] $\Delta A_{\text {conc }}=$ colour generated at the photostationary state after continuous UV irradiation of 1 molar of a given photochrome in solution, calculated as $\Delta \mathrm{A} /$ Concentration, $\Delta \mathrm{A}$ being the induced optical density at $\lambda_{\mathrm{Pss}}$. [h] $\mathrm{k}_{\Delta}=$ thermal bleaching rate constant. [i] $\mathrm{t}_{1 / 2}=$ thermal bleaching halflife. [j] EQ = emission quench (\%) calculated as the ratio of the intensity of emission at $\lambda_{\text {em }}$ of the PSS and closed-form. [k] after UV irradiation (365 nm, $\mathrm{Plamp}_{\text {la }} 8 \mathrm{~W}, 1 \mathrm{~min}$ ). [l] after visible light irradiation ( $405 \mathrm{~nm}, \mathrm{P}_{\text {lamp }} 1 \mathrm{~mW}, 1 \mathrm{~min}$ ).

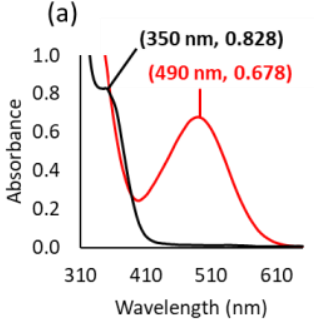

(c)

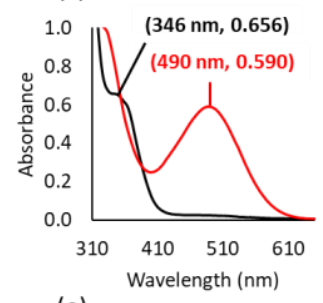

(e)

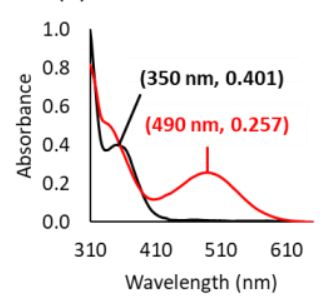

Fig. 1 (a) UV-Vis absorption spectra of 3a (black, $0.025 \mathrm{mM}$ ) and corresponding PSS (red, $\lambda_{\text {irr }} 325 \mathrm{~nm}, \mathrm{P}_{\text {lamp }} 150 \mathrm{~W}, 5 \mathrm{~min}$ ). (b) Bi-exponential fit of absorbance of PSS from $3 a$ at $490 \mathrm{~nm}$ in the dark $=f(t)$. (c) UV-Vis absorption spectra of $\mathbf{3 b}$ (black, $0.042 \mathrm{mM}$ ) and corresponding PSS (red, $\lambda_{\text {irr }}$ $325 \mathrm{~nm}, \mathrm{P}_{\mathrm{lamp}} 150 \mathrm{~W}, 3 \mathrm{~min}$ ). (d) Bi-exponential fit of absorbance of PSS from $\mathbf{3 b}$ at $490 \mathrm{~nm}$ in the dark $=\mathrm{f}(\mathrm{t})$. (e) UV-Vis absorption spectra of 3c (black, $0.025 \mathrm{mM}$ ) and corresponding PSS (red, $\lambda_{\text {irr }} 325 \mathrm{~nm}$, Plamp $150 \mathrm{~W}, 3 \mathrm{~min}$ ). (f) Bi-exponential fit of absorbance of PSS from $3 c$ at $490 \mathrm{~nm}$ in the dark $=f(t)$. All in degassed acetonitrile.

The highest lying $\mathrm{MO}$ of strong $\mathrm{M}$ character is HOMO-3 that plays a minor role in the $430 \mathrm{~nm}$ band $(<10 \%)$ but dominates in a weak band at $389 \mathrm{~nm}[\mathrm{f}=0.002]$ likely underneath the main $390 \mathrm{~nm}$ absorption. Evidently, excitation at the broad absorption band centred at ca. $350 \mathrm{~nm}$ of $\operatorname{Re}(\mathrm{I})$ complexes $\mathbf{3 a}-$ $3 c$ directly triggers a strong intra-ligand (IL) transition that has a CT character from the NP core to the pyridine moiety, besides a weak transition of metal-ligand-to-ligand charge-transfer (MLL'CT) character ${ }^{21}$ in which the electron density is displaced from the $\pi$ system of the whole $\operatorname{Re}(\mathrm{CO})_{3} \mathrm{NP}$ to the $\pi^{*}$ system of the electron-accepting bidentate ligand $\left(\mathrm{N}^{\wedge} \mathrm{N}\right)$.

Upon excitation at 382-394 $\mathrm{nm}$, structureless and broad emission bands centred at $490 \mathrm{~nm}$ (3a), $500 \mathrm{~nm}$ (3b) and 603 $\mathrm{nm}(3 \mathrm{c})$ are observed in degassed acetonitrile, with $\Phi_{\mathrm{em}}$ of 0.8 , 0.6 and $0.2 \%$, respectively (Table 1 and Fig. 2a). The decay of emission was fitted to a triexponential model with lifetimes $\tau_{1}=$ 4-7 ns, $\tau_{2}=36-74$ ns and $\tau_{3}=280-551$ ns (Table 1 and Fig. S43). Furthermore, the emission bands undergo a significant bathochromic shift with increasing solvent dielectric constant (Fig. 2b). Considering, the sensitivity of the emission energies to the electronic nature of the bidentate ligands, the moderately long emission lifetimes ${ }^{22}$ and the pronounced emission solvatochromism, ${ }^{23}$ the emission bands of $\mathbf{3 a}$ and $\mathbf{3 b}$ were assigned as being triplet metal-to-ligand charge-transfer ( $\left.{ }^{3} \mathrm{MLCT}\right)\left[\mathrm{d} \pi(\mathrm{Re}) \rightarrow \pi^{*}\right.$ (pytz)] phosphorescence. ${ }^{24}$ In both 3a and 3c, vertical TD-DFT returns three triplets below the lowest singlet at the FC geometry, so intersystem crossing (ISC) is possible to those three states. Nevertheless, for $\mathbf{3 a}$ only one triplet state could be located and minimized with U-DFT (Fig. S58). This triplet presents a 0-0 wavelength at $650 \mathrm{~nm}$, and exhibit a dominant IL character. The observed emission is therefore arising from a higher triplet of MLCT character, the emission being ineffective consistent with the poor $\Phi_{\mathrm{em}}$, as compared to other fac- $\left[\operatorname{Re}(\text { pytz })(\mathrm{CO})_{3} \mathrm{~L}\right]^{+}$complexes, ${ }^{25}$ which is a consequence of internal conversion (IC) to the lower-lying IL triplet state. The tailing of the recorded emission bands to lower energy, particularly notable for $\mathbf{3 b}$, may be attributed to weak mixed emission arising from triplets of IL character. This claim is supported by (i) the multiexponential fit of the emission decay suggesting the existence of multiple emissive events, including long-lived phosphorescent emission from triplets of MLCT and IL character, and short-lived fluorescent emission from the singlet excited state and (ii) by the excitation profiles recorded 
for $3 \mathbf{a}$ and $\mathbf{3 b}$ (Fig. $2 \mathrm{c}$ and $2 \mathrm{~d}$ ). Thus, the emission centred at 490-500 nm derives from an excitation band centred at 358$362 \mathrm{~nm}$, matching closely with the theoretical MLL'CT transition at $382 \mathrm{~nm}$. While the emission at $650 \mathrm{~nm}$ derives from a bathochromic-shifted excitation band centred at 383-390 nm, assigned as the IL transition ( $390 \mathrm{~nm}$ according to theory). For 3c, two triplet states could be located and minimized with $U$ DFT, the first of ligand-to-ligand charge transfer (LLCT) character and the second of IL character (Fig. S59). For the former a 0-0 phosphorescence wavelength of $587 \mathrm{~nm}$ was computed. For the latter, the corresponding value is $653 \mathrm{~nm}$. Considering the position of emission maximum at lower energy, it is predicted that the emission band of $3 c$ centred at $603 \mathrm{~nm}$ (see Fig. 2a) to be highly mixed and derived from emission of triplets of MLCT, LLCT and IL character. (a)

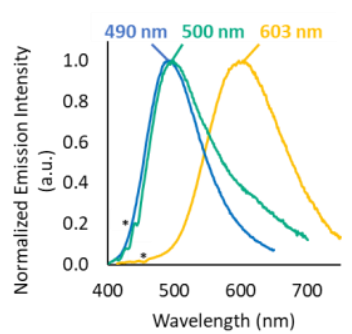

(c)



(b)

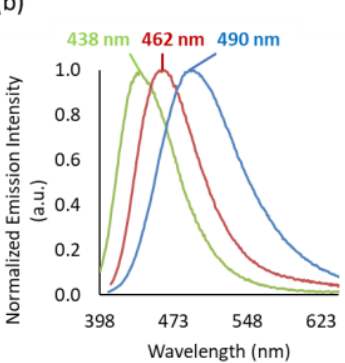

(d)



Fig. 2 (a) Normalized corrected emission spectra of 3a (blue, $0.019 \mathrm{mM}, \lambda_{\text {exc }}$ $392 \mathrm{~nm}$ ), 3b (cyan, $0.013 \mathrm{mM}, \lambda_{\text {exc }} 382 \mathrm{~nm}$ ) and $3 c$ (yellow, $0.023 \mathrm{mM}, \lambda_{\text {exc }} 394$ $\mathrm{nm}$ ) in degassed acetonitrile. (b) Normalized corrected emission spectra of $3 a$ (green, $0.034 \mathrm{mM}$ in degassed toluene, $\lambda_{\text {exc }} 388 \mathrm{~nm}$ ), $3 a$ (red, $0.016 \mathrm{mM}$ in a degassed mixture of dichloromethane:toluene (1:1), $\lambda_{\text {exc }} 394 \mathrm{~nm}$ ) and $3 a$ (blue, $0.019 \mathrm{mM}$ in degassed acetonitrile, $\lambda_{\mathrm{exc}} 392 \mathrm{~nm}$ ). (c) Normalized corrected excitation spectra of $\mathbf{3 a}(0.025 \mathrm{mM}$ in degassed acetonitrile) for emission at $490 \mathrm{~nm}$ (blue) and for emission at $650 \mathrm{~nm}$ (orange). (d) Normalized corrected excitation spectra of $\mathbf{3 b}(0.042 \mathrm{mM}$ in degassed acetonitrile) for emission at $490 \mathrm{~nm}$ (blue) and for emission at $650 \mathrm{~nm}$ (orange). *Raman scattering.

The $\operatorname{Re}(\mathrm{I})$ complexes $\mathbf{3 a - 3 c}$ exhibit UV-triggered photochromism affording red coloured solutions as a consequence of electrocyclic ring-opening of the pyran moiety (Fig. 1, Scheme 2). A photostationary state (PSS) could be established after only $20 \mathrm{~s}$ of continuous UV irradiation $\left(\lambda_{\text {irr }} 365 \mathrm{~nm}, \mathrm{P}_{\operatorname{lamp}} 8 \mathrm{~W}\right)$. Unlike the typical phototochromism of naphthopyrans, including $\mathbf{2 a , b}$ which exhibit photochromism when activated by UV radiation only; ${ }^{26}$ it is remarkable that the photochromic process of the complexes $\mathbf{3 a - 3 c}$ can be triggered by irradiation with visible light $\left(\lambda_{\text {irr }} 400-450 \mathrm{~nm}\right)$. This phenomenon is justified by the perturbation of the IL transition by coordination to the metal centre, ${ }^{27}$ which led to a bathochromic shift of the absorption band that tailed into the visible region. The photochromic reactions were accompanied by the evolution of intense and broad absorption bands centred at $490 \mathrm{~nm}$. The coloured PSS faded to the original colourless state either thermally or by assisted visible light irradiation $\left(\lambda_{\text {irr }}>455 \mathrm{~nm}\right.$ ). Bleaching in the dark followed a bi-exponential decay, typical of naphthopyran systems, ${ }^{28}$ with a first and second thermal bleaching rate constants in the order of $10^{-1} \mathrm{~s}^{-1}$ and $10^{-4} \mathrm{~s}^{-1}$, respectively (Fig. 1 and Table 1 ). For $\mathbf{4 a}$ and $\mathbf{4 c}$, theory predicts the existence of a strong absorption band in the visible centred at $528 \mathrm{~nm}[\mathrm{f}=$ $1.024]$ and $532 \mathrm{~nm}[f=1.031]$, respectively, of pure HOMO (NP) to LUMO (NP) character, correlating well with the experimental data (Fig. S60 and S61). In the vertical excitation spectra, only one lower triplet of the same ${ }^{3} \mathrm{IL}$ character can be found below the lowest singlet, i.e., triplet states of other character are higher than the lowest singlet in $\mathbf{4 a}$ and $\mathbf{4 c}$, meaning that ISC will only lead to the ${ }^{3} \mathrm{~L}$ triplet.


3a $\left(R=H, N^{\wedge} N=p y t z\right)$ 3b $\left(\mathrm{R}=\mathrm{OMe}, \mathrm{N}^{\wedge} \mathrm{N}=\right.$ pytz $)$ 3c $\left(\mathrm{R}=\mathrm{H}, \mathrm{N}^{\wedge} \mathrm{N}=\right.$ bpy $)$

$\mathrm{Ar}=4-\mathrm{MeOC}_{6} \mathrm{H}_{4}$

4a $\left(\mathrm{R}=\mathrm{H}, \mathrm{N}^{\wedge} \mathrm{N}=\right.$ pytz) 4b $(R=O M e), N^{\wedge} N=$ pytz) 4c $\left(\mathrm{R}=\mathrm{H}, \mathrm{N}^{\wedge} \mathrm{N}=\right.$ bpy)

Scheme 2 Photoisomerization of $\operatorname{Re}(\mathrm{I})$ complexes $\mathbf{3 a}-\mathbf{3 c}$.

Notably, the photochromic reaction led to efficient reversible photoquenching of the ${ }^{3} \mathrm{MLCT} \quad\left[\mathrm{d} \pi(\mathrm{Re}) \rightarrow \pi^{*}\left(\mathrm{~N}^{\wedge} \mathrm{N}\right)\right]$ phosphorescence. This phenomenon was particularly evident for $\mathbf{3 a}$ and $3 \mathrm{~b}$ in which $85 \%\left(\lambda_{\mathrm{em}} 490 \mathrm{~nm}\right)$ and $87 \%\left(\lambda_{\text {em }} 500 \mathrm{~nm}\right)$ of the ${ }^{3} \mathrm{MLCT}\left[\mathrm{d} \pi(\mathrm{Re}) \rightarrow \pi^{*}\right.$ (pytz)] phosphorescence was quenched after generation of the PSS with UV irradiation ( $\lambda_{\text {irr }} 365 \mathrm{~nm}$ ) (Table 1, Fig. 3). For $3 c$ (Table 1, Fig. S51), the photoquenching of the vertical emission at $603 \mathrm{~nm}$ was comparatively smaller (12\%), likely a result of the highly mixed triplet character of the emission band. Remarkably, the quenching of the ${ }^{3} \mathrm{MLCT}\left[\mathrm{d} \pi(\mathrm{Re}) \rightarrow \pi^{*}\right.$ (pytz)] phosphorescence could also be achieved by visible light irradiation ( $\left.\lambda_{\text {irr }} 400-450 \mathrm{~nm}\right)$, exemplified for $\mathbf{3 b}$ which displayed a vertical quench of emission at $500 \mathrm{~nm}$ of $79 \%$. In the photomerocyanines, $\mathrm{T}_{1}$ is strictly located on the ligand and it is very low in energy according to theory (ca. $1.4 \mathrm{eV}$ ). It is also the only triplet below the lowest singlet $\left(S_{1}\right)$. This contrasts with the naphthopyrans, in which three triplets (including the emissive ${ }^{3} \mathrm{MLCT}$ excited state) can be found below $\mathrm{S}_{1}$ (vide supra). In the naphthopyrans, ISC can first populate higher energy emissive triplet states $\left(T_{3}, T_{2}\right)$ that could then either emit a photon or IC to the dominant $T_{1}$. In the photomerocyanines, emission quenching is achieved by fast population of $S_{1}$ by IC followed by ISC to the only and dominant non-emissive (energy gap law) $\mathrm{T}_{1}$. Remarkably, for $\mathbf{3 b}$ the original cyan luminescence is absent in solution at the PSS (Fig. 3 cuvette images), being replaced by a very 
faint red luminescence which may be derived from an inefficient ISC between a higher $S_{n}$ and a higher $T_{n}$ of the photomerocyanine $\mathbf{4 b}$. Bleaching of the colour of the solutions of the PSS either thermally or with visible light, is accompanied by the regeneration of 3a-3c, and restoration of the initial luminescence. Moreover, these absorbance and emission changes are reversible over at least ten photochromic cycles under degassed conditions (Fig. S32, S35, S48 and S50). (a)

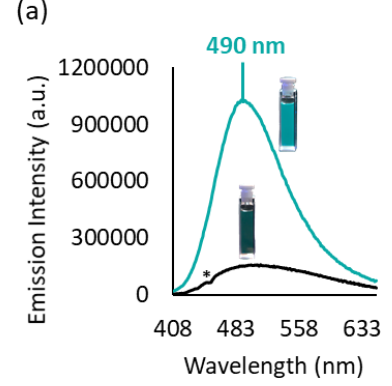

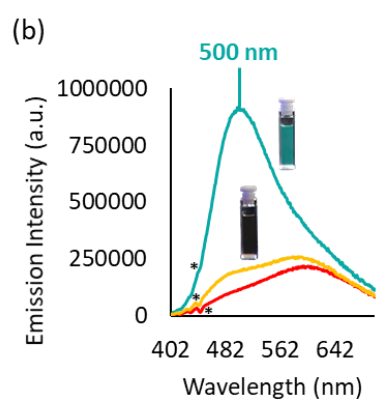

Fig. 3 (a) Corrected emission spectra of $3 a$ (cyan, $0.019 \mathrm{mM}$ ) and the PSS (black), $\lambda_{\text {exc }} 392 \mathrm{~nm}$ - PSS reached after UV irradiation ( $\lambda_{\text {irr }} 365 \mathrm{~nm}, \mathrm{P}_{\text {lamp }} 8 \mathrm{~W}$, $1 \mathrm{~min}$ ). (b) Corrected emission spectra of $\mathbf{3 b}$ (cyan, $0.042 \mathrm{mM}$ ) and the PSS, $\lambda_{\text {exc }} 382 \mathrm{~nm}-$ Yellow, PSS after visible light irradiation ( $\lambda_{\text {irr }} 405 \mathrm{~nm}, \mathrm{P}_{\text {lamp }} 1 \mathrm{~mW}$, $1 \mathrm{~min}$ ); Red, PSS after UV irradiation ( $\lambda_{\text {irr }} 365 \mathrm{~nm}, \mathrm{Plamp}_{\mathrm{a}} 2 \mathrm{~W}, 1 \mathrm{~min}$ ). All in degassed acetonitrile. *Raman scattering.

In summary, we have shown that the emission from the novel fac$\left[\operatorname{Re}\left(\mathrm{N}^{\wedge} \mathrm{N}\right)(\mathrm{CO})_{3} \mathrm{NP}\right]^{+}$complexes $3 \mathrm{a}-\mathbf{3 c}$ arises from a ${ }^{3} \mathrm{MLCT}$ excited state mixed in variable extent with emission from triplets of other characters. Complexes $\mathbf{3 a} \mathbf{3} \mathbf{3 c}$ exhibit photochromism at room temperature initiated by either visible light irradiation $\left(\lambda_{\text {irr }} 400-450\right.$ $\mathrm{nm}$ ) or by UV irradiation; such dual wavelength actuation of a naphthopyran system is both unique and remarkable. Of note is the ability to affect the bleaching both thermally and photochemically, the latter taken with visible light actuation, instead of higher energy UV, ${ }^{29}$ provides an advantageous example of a low energy switching system. The UV or visible light generated PSS are accompanied by up to $87 \%$ quenching of the ${ }^{3} \mathrm{MLCT} \quad\left[\mathrm{d} \pi(\operatorname{Re}) \rightarrow \pi^{*}\left(\mathrm{~N}^{\wedge} \mathrm{N}\right)\right]$ phosphorescence. The absorbance and emission changes exhibit fatigue resistance over at least ten cycles under degassed conditions. The novel fac- $\left[\operatorname{Re}\left(\mathrm{N}^{\wedge} \mathrm{N}\right)(\mathrm{CO})_{3} \mathrm{NP}\right]^{+}$complexes constitute a unique example of thermally reversible photochromes applied to the photoquenching of phosphorescence operational by either visible light or UV actuation.

\section{Author Contributions}

All authors contributed equally to this work. O. De Azevedo thanks the University of Huddersfield for funding this project and Thomas Broadbent for the acquisition of the photographs. D. Jacquemin is indebted to the CCIPL computational centre installed in Nantes for generous allocation of computational resources.

\section{References}

1 (a) C. Ko, V. W. Yam, Acc. Chem. Res., 2018, 51, 149; (b) E. C. Harvey B. L. Feringa, J. G. Vos, W. R. Browne, M. T. Pryce, Coordin. Chem. Rev., 2015, 282-283, 77

2 Photochromic Materials - Preparation, Properties and Applications, Ed. H. Tian, J. Zhang, Wiley-VCH (Germany), 2016.

3 K. A. Green, M. P. Cifuentes, T. C. Corkery, M. Samoc, M. G. Humphrey, Angew. Chem. Int. Ed., 2009, 48, 7867.

4 G. Markiewicz, A. Walczak, F. Perlitius, M. Piasecka, J. M. Harrowfield, A. R. Stefankiewicz, Dalton Trans., 2018, 47, 14254.

5 R. A. Kopelman, M. M. Paquette, N. L. Frank, Inorg. Chim. Acta, 2008 361, 3570.

6 J. Sun, L. Cai, Y. Chen, Z. Lib, J. Zhang, Chem. Commun., 2011, 47, 6870.

7 E. C. Harvey, J. Areephong, A. A. Cafolla, C. Long, W. R. Browne, B. L. Feringa, M. T. Pryce, Organometallics, 2014, 33, 447.

8 H. Le Bozec, V. Guerchais, C. R. Chimie, 2013, 16, 1172.

9 M. M. Paquette, B. O. Patrick, N. L. Frank, J. Am. Chem. Soc., 2011, 133, 10081.

10 B. A. McClure, E. R. Abrams, J. J. Rack, J. Am. Chem. Soc., 2010, 132 5428.

11 D. Rong, S. Gong, C. Wang, Q. Luo, Q. Li, Y. Xie, R. B. King, H. F. Schaefer, Inorg. Chem., 2017, 56, 14486.

12 (a) S. Bhattacharyya, M. Maity, A. Chowdhury, M. L. Saha, S. K. Panja, P. J. Stang, P. S. Mukherjee, Inorg. Chem., 2020, 59, 2083; (b) J. S. Park, A. M. Lifschitz, R. M. Young, J. Mendez-Arroyo, M. R. Wasielewski, C. L. Stern, C. A. Mirkin, J. Am. Chem. Soc., 2013, 135, 16988.

13 M. Kaiser, S. P. Leitner, C. Hirtenlehner, M. List, A. Gerisch, U. Monkowius, Dalton Trans., 2013, 42, 14749.

14 J. Liu, Dyes Pigm., 2019, 160, 476.

15 (a) R. C. Amaral, L. S. Matos, K. P. S. Zanoni, N. Y. M. Iha, J. Phys. Chem A, 2018, 122, 6071; (b) V. Sathish, E. Babu, A. Ramdass, Z. Lu, T. Chang, M. Velayudham, P. Thanasekaran, K. Lu, W. Li, S. Rajagopal, RSC Adv., 2013, 3, 18557

16 J. Liu, A. K. Chan, M. Ng, E. Y. Hong, N. M. Wu, L. Wu, V. W. Yam, Organometallics, 2019, 38, 3542.

17 Y. Lin, J. Yin, J. Yuan, M. Hu, Z. Li, G. Yu, S. H. Liu, Organometallics, 2010, 29, 2808.

18 (a) D. Joly, Y. Kervella, R. Demadrille, PCT Int. Appl., WO2018215371 A1, 2018; (b) S. Aiken, C. D. Gabbutt, B. M. Heron, C. S. Kershaw, N. J. Smith, J- P. Cano, US Patent, US8703978 B2, 2014.

19 C. -H. Chen, Y. -H. Liu, S. -M. Peng, J. -T. Chen, S. -T. Liu, Dalton Trans. 2012, 41, 2747.

20 O. D. C. C. De Azevedo, P. I. P. Elliott, C. D. Gabbutt, B. M. Heron, K. J. Lord, C. Pullen, J. Org. Chem., 2020, 85, 10772.

21 A. Vlček Jr, S. Záliš, Coord. Chem. Rev., 2007, 251, 258.

22 A. Vlček Jr, Top Organomet. Chem., 2010, 29, 73.

23 C. Ko, J. W. Siu, A. W. Cheung, S. Yiu, Organometallics, 2011, 30, 2701.

24 Y. Yue, T. Grusenmeyer, Z. Ma, P. Zhang, T. T. Pham, J. T. Mague, J. P. Donahue, R. H. Schmehl, D. N. Beratan, I. V. Rubtsov, J. Phys. Chem. $B, 2013,117,15903$.

25 P. A. Scattergood, A. Sinopoli, P. I. P. Elliott, Coordin. Chem. Rev., 2017, 350, 136

26 J. D. Hepworth, B. M. Heron in Functional Dyes, Ed. S.-H. Kim, Elsevier, (Amsterdam), 2006, pp. 85-135.

27 R. A. Kopelman, S. M. Snyder, N. L. Frank, J. Am. Chem. Soc., 2003 125, 13684

28 A. Alberti, Y. Teral, G. Roubaud, R. Faure, M. Campredon, Dyes Pigm., 2009, 81, 85.

29 O. S. Wenger, L. M. Henling, M. W. Day, J. R. Winkler, H. B. Gray, Inorg. Chem., 2004, 43, 2043.

\section{Conflicts of interest}

There are no conflicts to declare. 